This item was submitted to Loughborough's Research Repository by the author.

Items in Figshare are protected by copyright, with all rights reserved, unless otherwise indicated.

\title{
Investigation into the realisation of a low-SAR, dual mode material coated antenna for mobile handsets
}

PLEASE CITE THE PUBLISHED VERSION

PUBLISHER

(c) IEEE

VERSION

VoR (Version of Record)

\section{LICENCE}

CC BY-NC-ND 4.0

\section{REPOSITORY RECORD}

Kitra, Maria I., C.J. Panagamuwa, Patrick McEvoy, J.C. Vardaxoglou, and J.R. James. 2019. "Investigation into the Realisation of a Low-sar, Dual Mode Material Coated Antenna for Mobile Handsets". figshare. https://hdl.handle.net/2134/4994. 
This item was submitted to Loughborough's Institutional Repository (https://dspace.lboro.ac.uk/) by the author and is made available under the following Creative Commons Licence conditions.

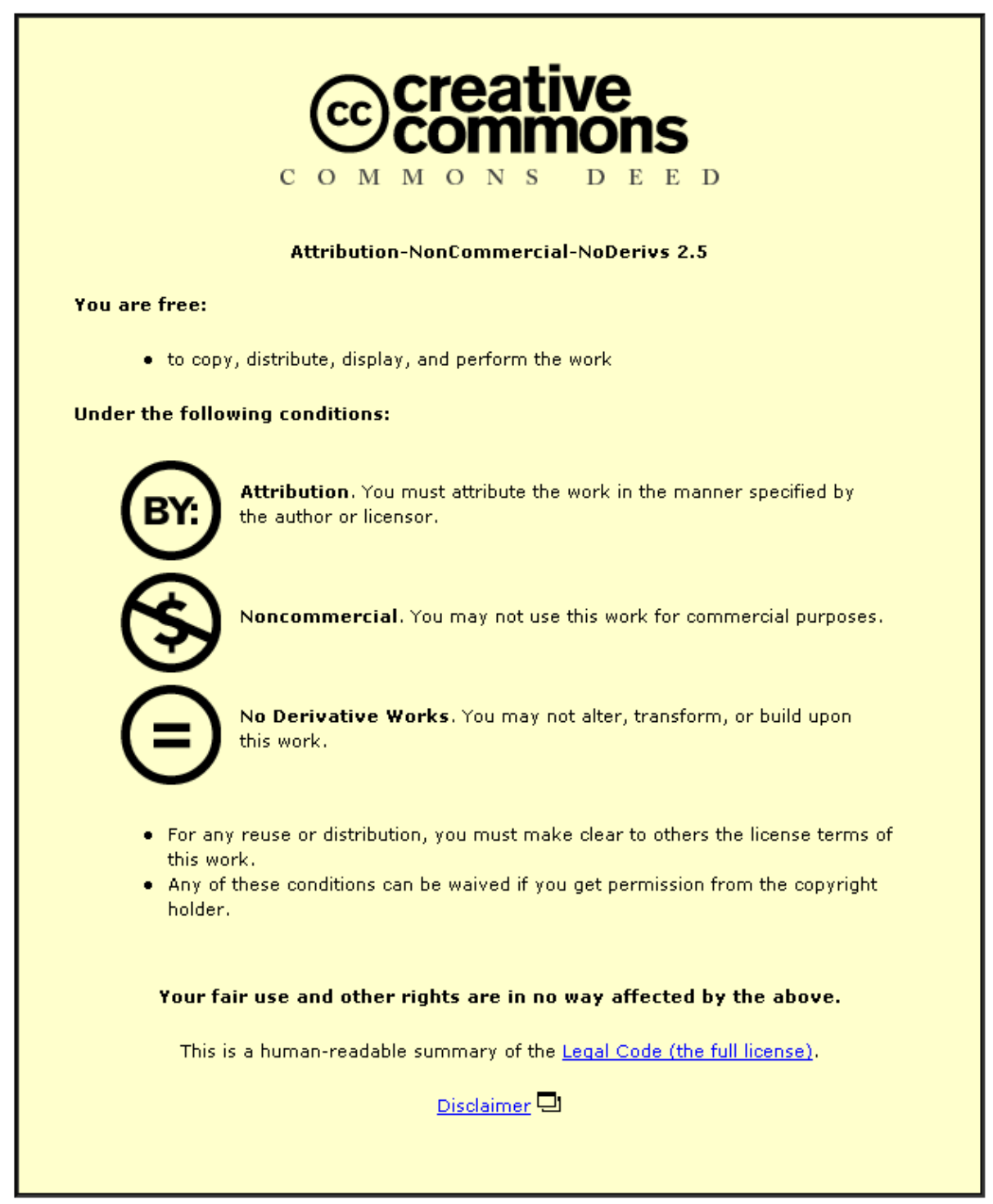

For the full text of this licence, please go to: http://creativecommons.org/licenses/by-nc-nd/2.5/ 


\title{
Investigation into the realisation of a low-SAR, dual mode material coated antenna for mobile handsets
}

\author{
M.I. Kitra, C.J. Panagamuwa, P. McEvoy, J.C. Vardaxoglou, J.R. James - CMCR \\ Loughborough University, UK
}

\begin{abstract}
Previous theoretical and experimental work on material loaded antennas illustrated that choosing a material mix containing equal permittivity and permeability in combination with specific positioning of the antenna in relation to the head can produce the definitive small size, high efficiency, low Specific Absorption Rate (SAR) antenna. Further results obtained from a TLM simulator indicate the antenna's ability to operate in wideband dual mode and provide design guidelines for its realisation. New materials are tested and design-engineering techniques are explored, towards the ultimate aim of realising and integrating the antenna into the handset.
\end{abstract}

\section{Introduction}

The use of high permitivity ceramic material in mobile antennas has proved a useful means of compacting the antenna but the bandwidth and radiation efficiency can be significantly reduced. More recently it has been shown that a material having both a permittivity and permeability is able to reduce antenna size while maintaining the bandwidth and efficiency $[1$, 2]. The introduction of permeability also gives additional design freedom regarding the magnetic and electric composition of the near fields and this has implications for the reduction of the Specific Absorption Rate (SAR) [2,3]. In the present paper the ability of this new ferrite-based antenna concept to operate in dual mode is examined and simulations illustrate the significant increase in bandwidth that can be obtained. This is particularly attractive in view of the escalating need of handset manufacturers to cover several operational bands with a single antenna.

Practical issues regarding the realisation of this antenna are considered and a composite version consisting of layers of ceramic and magnetic materials is investigated to assist with the choice and deployment of commercially available ferrite materials. Also described are efficiency measurements of MF112, a material by Emerson and Cuming, containing $\varepsilon_{r}=5.2$ and $\mu_{r}=1.4$. Finally, the progress translating the above attributes of widebandwidth, good efficiency and low SAR into a "chip-type " antenna device, will be summarised.

\section{Optimum material composition}

The performance benefits of introducing permeability into dielectric resonator antennas were initially established with an analytical model based on a ceramic spherical resonator excited by a small wire probe or loop [1]. Subsequently extensive simulation of rectangular and other irregular shapes using Flomerics Microstripes TLM has confirmed the generality of the benefits $[2,3]$. For any particular mode the efficiency and bandwidth are maximised when the permeability and permittivity are of comparable values and the antenna SAR reduces by an order when the axis of symmetry of the antenna is perpendicular to the head. We now describe how to increase the bandwidth further. 


\section{Wide band dual mode action}

The additional design freedom associated with the use of both permeability and permittivity in the antenna coating material enables some additional control of the frequency separation between adjacent modes and hence the opportunity to obtain wideband dual mode operation by coupling together two adjacent modes. For non-spherical antennas the ratio of the antenna height to width is also a parameter that influences mode coupling giving even further design freedom [4]. These effects are illustrated in Figure $I$ that shows the return loss of a cube antenna (side $=30 \mathrm{~mm}, \tan \delta=0.01$ ) sourced by a wire-fed dipole, for different ratios of permittivity and permeability. In this case, the frequency of operation is kept constant at $1.8 \mathrm{GHz}$ by varying the $\varepsilon_{r}^{*} \mu_{r}$ product, however the permeability values remain comparable to the theoretical model.

Two transverse magnetic resonances are observed, excited by the electric dipole inside the cube. These first two resonances have similar radiation patterns to the $T M_{101}$ and $T M_{102}$ modes of a spherical resonator. This dual resonance characteristic varies with the ratio of permittivity and permeability. As the permittivity is increased, the two modes come together and create a wideband radiation characteristic. The maximum $-10 \mathrm{~dB}$ bandwidth in this case is $7 \%$ and is noted when $\varepsilon_{r}=\mu_{r}=6$. The result is very important from a design and communications point of view and hence simulations took place to improve it even further. This was achieved by varying the length of the dipole and $\mu_{r}$ in order to obtain the best match at $1.8 \mathrm{GHz}$ and consequently the widest bandwidth.

Figure 2 shows the bandwidth variation of the same antenna, for $\tan \delta=0.01$ and $\tan \delta=0.03$, before and after it was optimised by adjusting the probe length. The permeability varies in a fashion similar to Figure $l$ and the improvement is significant in both cases. For $\tan \delta=0.01$, the maximum bandwidth is $7.9 \%$ at $\varepsilon_{r}=9, \mu_{r}=3.3$ and for $\tan \delta=0.03$ it is $13.6 \%$ for the same ratio. This is an increase of $1.4 \%$ and $4 \%$ respectively. The efficiency and $10 \mathrm{gSAR}$ deviation, which resulted from the optimisation, was minimal and isn't presented.

Having established the combination of the presence of permeability and close proximity of the first two $T M$ modes results in wideband operation and increased efficiency, simulations were run to determine how the antenna shape affects the aforementioned characteristics.

\section{Effect of the aspect ratio}

A rectangular antenna with dimensions $40 \times 20 \times 20 \mathrm{~mm}$ and a width to height ratio of 0.5 was modelled, using loss tangents of 0.01 and 0.03 respectively. Comparing its performance to the results from the previously simulated cube antenna (width to height ratio of 1) indicated the effect of the aspect ratio and provided additional design guidelines towards the practical realisation of the antenna.

Figure 3 shows the return loss of both antennas for $\tan \delta=0.01$. As the aspect ratio decreases, the $-10 \mathrm{~dB}$ bandwidth increases by $5 \%$. The efficiency and $10 \mathrm{gSAR}$ variation of the same antennas are illustrated in Figure 4. The rectangular antenna exhibits $3.7 \%$ increase in efficiency and $12 \%$ decrease in $10 \mathrm{gSAR}$. It is concluded that a reduction in the width to height ratio enhances the wideband dual operation and general performance of the antenna.

\section{Measurement Substantiation}

There are two main issues that need attention regarding the practical realisation of such an antenna: the acquisition of appropriate material with high permeability and low losses at microwave frequencies and the transformation of the generic monopole antenna into a planar chip device that will allow its integration in the handset.

Previous efforts to address the first issue resulted in demonstrator measurements [3], which validated the accuracy of the simulation package. Two new materials have now been tested. 
The first was Emerson and Cuming's MF1 12 iron loaded epoxy material. It has the following properties: $\varepsilon_{r}=5.2, \mu_{r}=1.4, \tan \delta_{\varepsilon}=0.05$ and $\tan \delta_{\mu}=0.03$. The material was provided as a cuboid with length, width and height of 25,25 and $27 \mathrm{~mm}$ respectively.

A $1 \mathrm{~mm}$ hole was created at its centre to host a $12 \mathrm{~mm}$ monopole with a ground plane. The structure resonated at $2.45 \mathrm{GHz}$ with $-18 \mathrm{~dB}$ retum loss and had $44 \%-10 \mathrm{~dB}$ bandwidth. The Wheeler cap test was conducted and indicated an efficiency of $63 \%$. The antenna was then simulated using Flomerics Microstripes and produced $-12 \mathrm{~dB}$ at $2.414 \mathrm{GHz}$ with efficiency $66.55 \%$. The agreement between the two was excellent again substantiating the software as a teliable prediction tool.

The next material tested was a commercially available flexible sheet of ferrite loaded material intended for use as a white board marker. Research had indicated that it might contain hexagonal ferrite, which has suitable properties for this application. The material was cut in $20 \mathrm{~mm}$ squares, which were stacked to form a rectangle of $30 \mathrm{~mm}$ height. The material was then drilled to cover a $12 \mathrm{~mm}$ monopole and the structure resonated at $2.43 \mathrm{GHz}$ with $10.6 \mathrm{~dB}$ return loss and $83 \%$ efficiency. The $\varepsilon_{r}{ }^{*} \mu_{r}$ product of this material had been approximately ascertained by some initial testing and its properties were estimated from the convergence of the simulations to reality. The following characteristics gave $-13.4 \mathrm{~dB}$ at $2.418 \mathrm{GHz}$ with an efficiency of $78 \%: \varepsilon_{r}=4.3, \mu_{r}=1.4, \tan \delta_{\varepsilon}=0.03$ and $\tan \delta_{\mu}=0.02$.

\section{Introducing flexibility inte material realisation}

Both the above materials had too low an $\varepsilon_{r}{ }^{*} \mu_{r}$ product for translation into a compact chip design for a handset and the concept of a composite antenna was investigated whereby the material parameters could to some extent be chosen independently of one another. As a first step a $30 \times 30 \times 30 \mathrm{~mm}$ composite block antenna was simulated consisting of ferrite material in its lower region around the probe to a height of $10 \mathrm{~mm}$. The remainder of the antenna volume consisted of dielectric material alone.

The response obtained was similar to the homogeneous case for varying $\varepsilon_{r}, \mu_{r}$ but the efficiency and bandwidth were significantly reduced as shown in Figure 5. In other simulations the composite antenna consisted of altemate $2.5 \mathrm{~mm}$ layers of dielectric and ferrite material. It resulted in the antenna behaviour varying inconsistently between the homogeneous and the single ferrite layer response; this was attributed to scattering between the layers. It was concluded that the homogeneous material is essential to realise the bandwidth and efficiency potential of this type of antenna.

\section{Chip Practical Realisation}

Current research is in progress on the translation of the desirable high efficiency, wide bandwidth and low SAR antenna features into a more compact embedded handset antenna. At present the prospects of preserving these features are good and an estimation, based on a spherical shaped antenna, of how the $\varepsilon_{r}{ }^{*} \mu_{r}$ product increases with the reduction of the volume allocated to the handset antenna, is given in Figure 6.

\section{Conclusions}

* Simulations and measurements continue to confirm the reliability of the modelling and establish the wide band operation resulting from the dual mode action.

* The low SAR properties for these antenna configurations are maintained.

* Simulations on a composite antenna arrangement confirm that homogeneous material is necessary for optimum antenna performance

* Higher values of permittivity and permeability are required for embedding the antenna into a handset and the practical realisation is currently being investigated. 


\section{References}

[1] Kitra, M.I., McEvoy, P., Vardaxoglou, J.C., James, J.R.: " A Theoretical and Simulation Study of Dielectrically Loaded Antennas and their Contribution Towards Low-SAR ", International ITG

Conference on Antennas (INICA), September 2003, pp.245-8.

[2] Kitra, M.I., McEvoy, P., Vardaxoglou, J.C., James, J.R.: "A Theoretical and Experimental Study of Dielectrically Loaded Antennas and their Contribution Towards Low-SAR", 2004 IEEE AP-S

Intemational Symposium on Antennas and Propagation and USNC/URSI National Radio Science Meeting, June 2004,pp.3593-3596.

[3] Kitra, M.I., McEvoy, P., Vardaxoglou, J.C., James, J.R.: "Material Loaded Antennas and their Contribution Towards Low-SAR", 2004 IEE Antennas Measurements and SAR Conference,

Loughborough University, UK, May 2004.

[4] James, J.R., Chair, R., Luk, K.M., Chow, K.M., Leung, K.W., Vardaxoglou, J.C.: "Influence of magnetic material on dielectric resonator antemna excitation", IEE Proceedings Microwave Antennas and Propagation, Vol.15I, No.4, August 2004

The authors acknowledge the contribution of Flomerics and the use of their MicroStripes TLM modelling tool.

This work was supported by the UK EPSRC, Grant number GR/R94596/01.

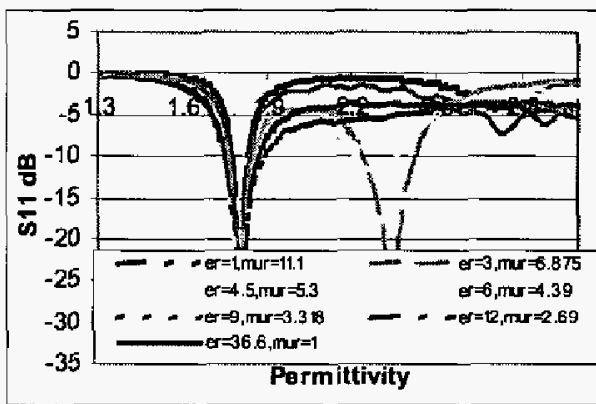

Figure l - Return loss of cube antenna

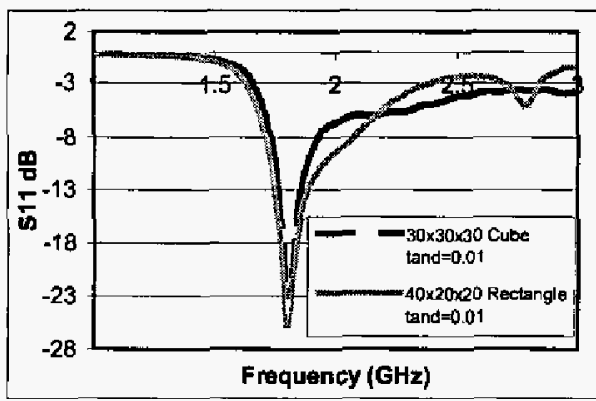

Figure 3 - Aspect ratio effect on return loss

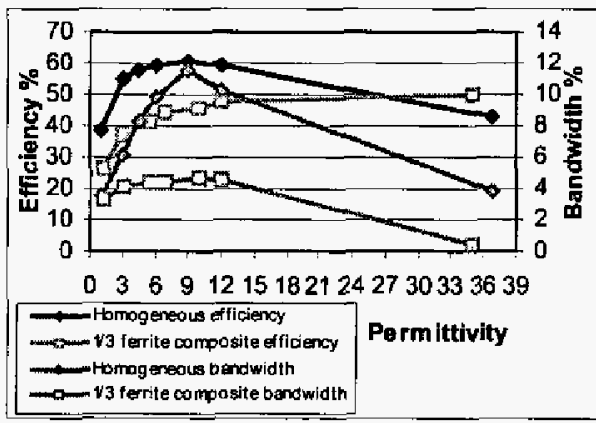

Figure 5 - Composite efficiency and bandwidth

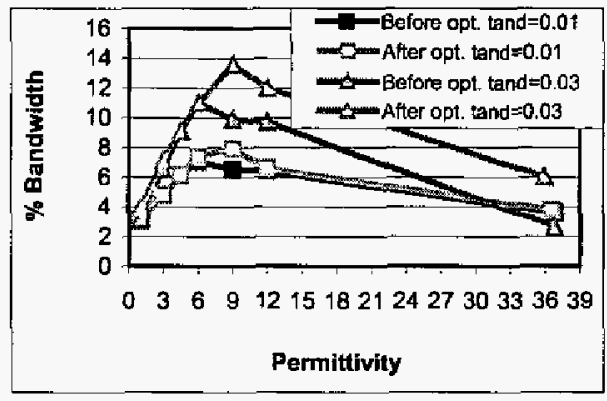

Figure 2 - Bandwidth variation of cube antenna

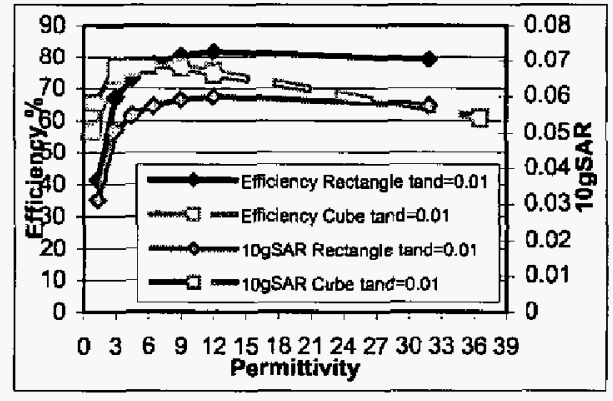

Figure 4 - Aspect ratio effect on efficiency and SAR

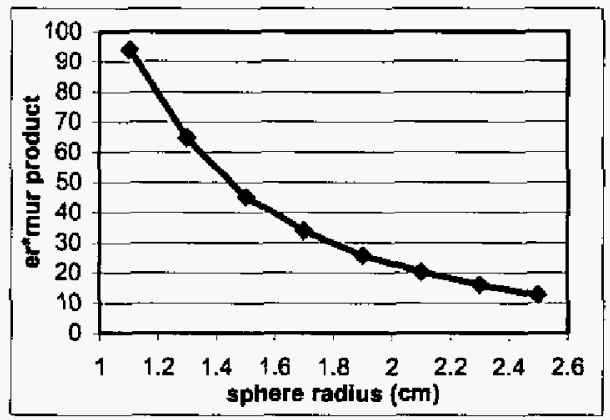

Figure $6-\varepsilon_{r}^{*} \mu_{r}$ product with volume 